Jurnal Widya Laksana, Vol.10, No.1, Januari 2021

\title{
IMPLEMENTASI APLIKASI SISTEM INFORMASI DESA DAN KEPENDUDUKAN BERBASIS WEB DI DESA KUKUH KERAMBITAN
}

\author{
Wayan Gede Suka Parwita ${ }^{1}$, Rizkita Ayu Mutiarani ${ }^{2}$, I Nyoman Widhi Adnyana ${ }^{3}$ \\ 1,2,3Teknik Informatika, STMIK STIKOM Indonesia \\ e-mail: ${ }^{2}$ gede.suka@gmail.com, ${ }^{2}$ ayumutiarani@stiki-indonesia.ac.id, \\ ${ }^{3}$ manwidhi@stiki-indonesia.ac.id
}

\begin{abstract}
Abstrak
Tidak adanya tenaga ahli bidang Teknologi Informasi dan adanya keterbatasan akses pengetahuan hingga pendanaan di Desa Kukuh mengakibatkan sulitnya implementasi keterbukaan informasi publik berbasis Teknologi Informasi. Pengabdian masyarakat ini bertujuan untuk membantu aparatur pemerintahan desa mengimplementasikan Sistem Informasi Desa dan Kependudukan Berbasis Web di Desa Kukuh Kecamatan Kerambitan Kebupaten Tabanan. Pengabdian kepada masyarakat ini dipolakan dengan 3 (tiga) tahapan, yaitu 1) tahap pendaftaran Domain.desa.id ke Kementerian Komunikasi dan Informatika; 2) tahap penyiapan server \& hosting dengan memanfaatkan jasa para vendor web hosting, serta 3) implementasi Sistem Informasi Desa dan Kependudukan. Pelaksanaan pengabdian ini dilakukan dalam bentuk kegiatan partisipasi perguruan tinggi melalui pendekatan terhadap sumber daya yang ada di mitra pada Pemerintahan Desa Kukuh Kecamatan Kerambitan kabupaten Tabanan. Bentuk kegiatan bertahap dan terdistribusi dalam 3 bulan. Pelaksanaan pengabdian kepada masyarakat tentang implementasi sistem informasi desa dan kependudukan di Desa Kerambitan Tabanan telah terlaksana dengan maksimal dan telah dapat diakses pada kukuh.desa.go.id.
\end{abstract}

Kata kunci: Desa Kukuh, Sistem Informasi Desa

\begin{abstract}
The absence of expert in information technology and limited access to knowledge and funding in Kukuh Village resulted in the difficulty of implementing information technology-based public information disclosure.This community service aims to help village government officials implement a Web-Based Village and Population Information System in Kukuh Village, Kerambitan District, Tabanan Regency. This community service is denoted by 3 (three) stages, namely 1 ) Domain.desa.id registration to the Ministry of Communication and Information; 2) the server \& hosting preparation stage by utilizing the services of web hosting vendors, and 3) the implementation of the Village and Population Information System. The implementation of this service is done in the form of higher education participatory activities through an approach to the resources available in partners in the Government of the Kukuh Village, Kerambitan District, Tabanan Regency. Forms of phased and distributed activities in 3 months. Information System Implementation in Kukuh-Tabanan has been carried out optimally and can be accessed at ksukuh.desa.go.id.
\end{abstract}

Keywords : Kukuh Vilage, Vilage Information System

\section{PENDAHULUAN}

Sebagai dampak perkembangan
teknologi informasi bagi apatur pemerintahan terlebih dengan berlakunya Undang-Undang No. 14 Tahun 2008, tentang Keterbukaan Informasi Publik adalah salah satu produk hukum Indonesia yang dikeluarkan dalam tahun 2008 dan diundangkan pada tanggal 30 April 2008, serta mulai berlaku dua tahun setelah diundangkan (UU No. 14, 2008). Undangundang yang terdiri dari 64 pasal ini pada intinya memberikan kewajiban kepada setiap Badan Publik untuk membuka akses bagi setiap pemohon informasi publik untuk mendapatkan informasi publik, kecuali beberapa informasi tertentu dalam upaya mewujudkan tata kelola pemerintahan yang baik (Wibawa, K. C. S. 2019). 
Sejalan dengan kebijakan hukum tersebut, maka setiap instansi pemerintahan sebagai salah satu badan publik di Wilayah Kesatuan Republik Indonesia wajib untuk memberikan informasi yang layak secara terbuka kepada seluruh lapisan masyarakat (Setligt, A. O. 2017). Oleh karena adanya kewajiban bagi para penyelenggara pemerintahan mulai dari level atas hingga bawah maka upaya-upaya strategis dan efektif dalam rangka menyajikan informasi layak bagi publik pun dilakukan.

Salah satu langkah tepat dalam rangka mempublikasikan informasi kepemerintahan kepada masyarakat untuk saat ini adalah dengan memanfaatkan teknologi informasi terlebih dengan berkembangnya teknologi informasi yang hingga kini cukup diakses melalui genggaman saja, maka hal ini semakin diyakini dapat dijadikan media dalam rangka mentransfer informasi layak kepada publik atau masyarakat (Riyanto, I. Santiko, and A. M. Wahid, 2018).

Pemerintahan Desa adalah salah satu satuan pemerintahan dilevel paling bawah. Pemerintahan Desa dengan sokongan beberapa satuan wilayah terkecil dalam Desa tersebut memiliki lebih dari satu penduduk bahkan hingga jutaan orang penduduk tergantung luas wilayah dan tingkat kelahiran masyarakat dalam desa tersebut. Sehingga dalam rangka memenuhi Undang-Undang No. 14 Tahun 2008, tentang Keterbukaan Informasi Publik, aparatur Desa dengan berbagai upaya harus dapat melakukan inovasi secara tepat, sehingga tujuan kebijakan hukum tersebut tercapai sesuai dengan maksud dan tujuannya.

Dalam rangka implementasi maksud dan tujuan Undang-Undang No. 14 tahun 2008, tentang Keterbukaan Informasi Publik tersebut di Desa Kukuh Kecamatan Kerambitan Kabupaten Tabanan dengan luas wilayah 2,76 $\mathrm{Km}^{2}$ dan dengan jumlah penduduk 2.333 jiwa (Kariadi, I. N. 2017), sejak dicanangkan pada pertengahan tahun 2017 hingga saat ini (awal 2019), pihak aparatur Desa Kukuh belum mampu mengimplementasikan keterbukaan informasi pemanfaatan Sistem Informasi Desa dan Kependudukan Berbasis Web.
Ketidakmampuan aparatur desa dalam mengimplementasikan keterbukaan informasi publik tersebut melalui pemanfaatan teknologi informasi khususnya pemanfaatan Sistem Informasi Desa dan Kependudukan Berbasis Web disebabkan oleh tidak adanya tenaga ahli bidang Teknologi Informasi dan adanya keterbatasan akses pengetahuan hingga pendanaan, meskipun aplikasi Sistem Infomasi Desa dan Kependudukan Berbasis Web tersebut merupakan perangkat lunak yang dapat dimanfaatkan secara bebas (free) oleh pemerintahan desa. Oleh sebab itu, kehadiran para ahli dan praktisi dalam rangka implementasi aplikasi Sistem Informasi Desa dan Kependudukan Berbasis Web sangat dibutuhkan.

\section{METODE}

Pelaksanaan pengabdian ini dilakukan dalam bentuk kegiatan partisipasi perguruan tinggi melalui pendekatan terhadap sumber daya yang ada di mitra yaitu pada Pemerintahan Desa Kukuh Kecamatan Kerambitan Kabupaten Tabanan. Bentuk kegiatan ini dilakukan bertahap dan terdistribusi dalam 3 bulan. Kegiatan tersebut meliputi:

1) Tahap pendaftaran Domain.desa.id ke Kementerian Komunikasi dan Informatika;

2) Tahap penyiapan server dan hosting dengan memanfaatkan jasa para vendor web hosting, serta

3) Implementasi Sistem Informasi Desa dan Kependudukan.

Pada akhirnya indikator keberhasilan yang dicapai adalah Sistem Informasi Desa dan Kependudukan Berbasis Web di Desa Kukuh Kecamatan Kerambitan Kabupaten tabanan telah selesai diimplementasi dan telah terpublikasi secara online.

\section{HASIL DAN PEMBAHASAN}

Penerapan Undang-Undang No. 14 Tahun 2008 mengakibatkan diperlukannya sebuah sistem administrasi desa dan kependudukan yang terstruktur. Penerapan ini dapat didukung dengan implementasi Sistem Informasi Desa dan Kependudukan. Adapun implementasi ini dilakukan dengan beberapa tahapan sebagai berikut. 
1) Pendaftaran Domain

Domain kukuh.desa.id didaftarkan pada Kementerian Komunikasi dan Informatika Republik Indonesia. Tujuan dibuatkan domain kukuh.desa.id adalah mempermudah aparatur desa Desa Kukuh dalam melaksanakan Undang-Undang No. 14 Tahun 2008, tentang Keterbukaan Informasi Publik yang akan disampaikan kepada penduduk Desa Kukuh Kecamatan Kerambitan Kabupaten Tabanan.

Sebelum mendaftarkan domain kukuh.desa.id, beberapa berkas yang harus dipersiapkan, antara lain (Kemkominfo, 2016):

a. SK Pengangkatan Perangkat Desa (khususnya bagi yang mendaftarkan domain desa.id) yang telah ditandatangani Kepala Desa dengan format file JPEG maksimal $256 \mathrm{~KB}$.

b. SK Pengangkatan Kepala Desa yang ditandatangani oleh Bupati dengan format file gif, JPEG, atau PDF dengan ukuran maksimal $256 \mathrm{~KB}$.

c. Surat Permohonan Resmi yang ditujukan kepada Menteri Komunikasi Dan Informasi Republik Indonesia dengan file gif, JPEG, atau PDF dengan ukuran maksimal $256 K B$.

d. Surat Kuasa sebagai pengelola domain desa.id bermaterai Rp6.000,- dengan format file gif, JPEG, atau PDF dengan ukuran maksimal $256 \mathrm{~KB}$.

e. KTP/SIM/Paspor Kepala Desa dengan format file gif, JPEG, atau PDF dengan ukuran maksimal $256 \mathrm{~KB}$.

f. KTP/SIM/Paspor Perangkat Desa yang tertera dalam Surat Kuasa dengan format file gif, JPEG, atau PDF dengan ukuran maksimal $256 \mathrm{~KB}$.

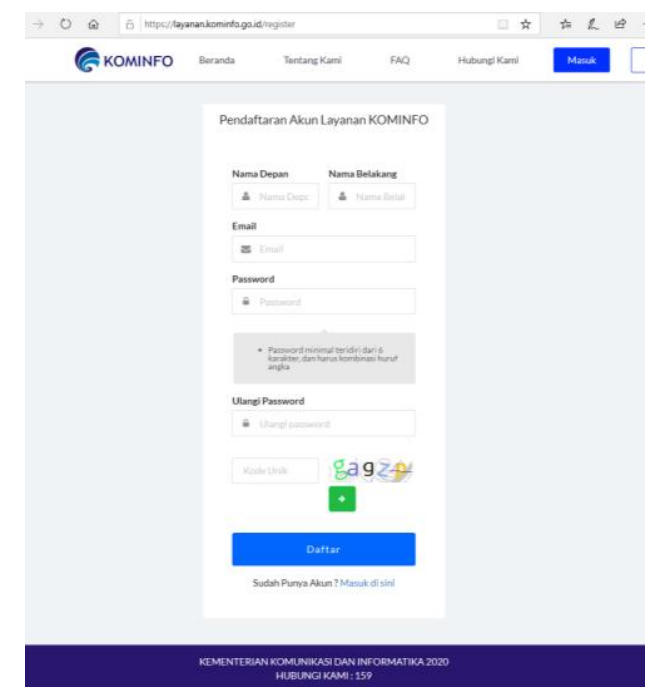

Gambar 1. Tampilan Form Registrasi

Setelah mendaftar, Perangkat Desa menerima email aktivasi dan mendapatkan username dan password untuk untuk mendaftarkan domain desa.id. Setelah semua proses dilalui maka domain kukuh.desa.id dapat digunakan. Semua kebutuhan dokumen dan proses dalam tahap ini dapat terlaksana dengan baik berkat kerjasama aparatur Desa Kukuh.

2) Pembuatan

Subdomain

simdes.kukuh.desa.id

Server sistem informasi Desa Kukuh menggunakan kontrol panel cPanel. Melalui cPanel anda dapat mengelola fasilitas web hosting, seperti membuat dan mengelola email account untuk website, menginstal WordPress (atau CMS lain seperti Joomla, Prestashop, dsb), backup file website, mengunggah file, mengecek pemakaian bandwidth dan disk space, dan masih banyak lagi [7].

Dalam cPanel juga terdapat pengelolaan fasilitas untuk membuat subdomain kukuh.desa.id. Fasilitas ini terdapat pada bagian "Domain". Bagian "Domains" pada cPanel memungkinkan Anda untuk mengelola segala hal yang berhubungan dengan domain. Sub domain yang digunakan untuk sistem informasi Desa Kukuh yaitu simdes.kukuh.desa.id. 


\section{Create a Subdomain}

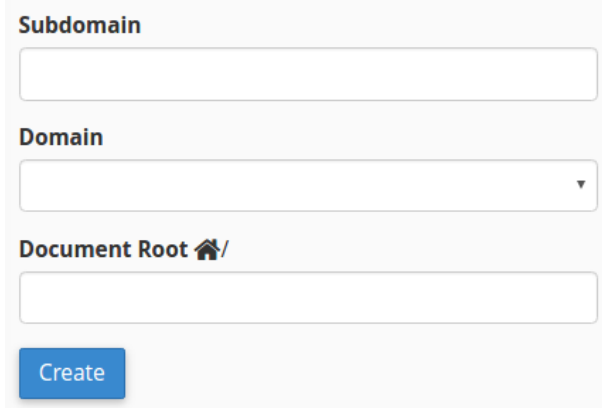

Gambar 2 Tampilan menu domain

Penambahan subdomain dapat dilakukan pada menu "Subdomain". Gambar 2 merupakan halaman untuk mengisi peraturan yang dibutuhkan dalam pembuatan subdomain. Adapun yang diisi, yaitu:

\section{a. Subdomain}

Mengisi dengan nama subdomain yang digunakan. Pada bagian ini hanya ekstensi subdomain yang dimasukkan. Subdomain diisi dengan "simdes".

b. Domain

Memilih domain yang ditambahkan subdomain. Domain diisi dengan "kukuh.desa.id".

c. Document Root

Folder untuk menyimpan website yang digunakan pada subdomain. Folder ini dibuat dalam direktori public_html.

Setelah pengaturan dilakukan, maka semua file website diupload ke server dan simdes.kukuh.desa.id siap digunakan.

\section{3) Hosting Website}

Pengembangan tahap awal sistem informasi Desa Kukuh menggunakan Shared Hosting. Shared Hosting merupakan layanan hosting diletakkan bersama beberapa account hosting lain dalam satu server yang sama, dan memakai services bersama-sama (Mirheidari, S. Arshad, and S. Khoshkdahan, 2012). Pemilihan shared hosting mempertimbangkan kebutuhan sumber daya untuk sistem informasi desa saat ini. Kebutuhan tahap awal untuk sistem informasi desa yaitu akses untuk setiap perangkat desa untuk memasukkan data pada masing-masing bidang seperti data kependudukan, surat menyurat, dan keuangan desa. Shared hosting juga digunakan karena mempertimbangkan anggaran yang dapat digunakan dalam kegiatan pengabdian kepada masyarakat. Adapun sebagai pertimbangan lain, yaitu:

a. Pengelolaan sistem informasi di Desa Kukuh cukup dimudahkan, karena tidak perlu direpotkan dengan setting server.

b. Layanan hosting menyediakan support yang siap membantu selama 24 jam.

c. Jika ada permasalahan pada server, penyedia server akan memperbaiki permasalahan tersebut.

Sistem informasi Desa Kukuh menggunakan hosting dengan spesifikasi:

a. 2 GB Disk Space

Penggunaan $2 G B$ disk space dirasa cukup karena mempertimbangkan ukuran Open SID yang hanya $62 \mathrm{MB}$. Selain itu diperlukan beberapa gambar yang disimpan untuk slider dan database untuk mendukung sistem informasi Desa Kukuh. Data untuk email juga belum besar karena email Perangkat Desa belum sepenuhnya memanfaatkan fasilitas email desa.

b. 80 GB Bandwidth

Bandwidth adalah besaran hitungan transfer data yang terjadi antara server hosting dengan komputer pengakses [9].

Semakin banyak pengakses maka penggunaan bandwidth akan semakin besar. Untuk penggunaan di lingkungan perangkat desa, 80 GB untuk bandwidth sudah mencukupi. Penambahan bandwidth diperlukan apabila sistem telah berjalan penuh dan pengakses sistem juga semakin banyak.

c. Unlimited Email

Penggunaan email desa sangat disarankan. Hal ini juga telah menjadi himbauan di kalangan institusi pemerintahan. Ada beberapa hal yang menjadi pertimbangkan yaitu keamanan dan branding. Untuk pertimbangan keamanan, email gratis seperti gmail dan yahoo mail dinilai mudah dieksploitasi. Ini dikhawatirkan menjadi salah satu sumber kebocoran informasi. Untuk pertimbangan branding akan mempermudah perangkat desa untuk mengenalkan Desa Kukuh sebagai desa pintar dan desa digital. 
d. cPanel Control Panel

cPanel merupakan control panel hosting yang memiliki tampilan interface menarik, fitur yang lengkap dan pengguna paling banyak diantara control panel hosting yang lainnya. Hal ini akan memudahkan karena mempelajari control panel ini tidak sulit dan tutorial cPanel juga mudah ditemukan.

4) Implementasi OpenSID

OpenSID merupakan sistem informasi desa dengan kode terbuka. Fokus dari OpenSID yaitu membantu perangkat desa dalam pengelolaan data desa. OpenSID juga diharapkan turut membantu \pm 74 ribu desa di Indonesia agar dapat menerapkan sistem informasi untuk memajukan desanya. Dalam pengembangan sistem informasi untuk Desa Kukuh Kecamatan Kerambitan Kabupaten Tabanan, OpenSID merupakan pilihan tepat. Hal ini menimbang ketersediaan anggaran dan dukungan komunitas. OpenSID merupakan sistem informasi gratis yang dapat digunakan oleh desa dimana saja, sehingga anggaran dapat difokuskan pada anggaran untuk hosting dan penggunaan domain. Dukungan komunitas saat ini masih kuat sehingga kelangsungan dan dukungan sistem informasi dapat terjamin $(\mathrm{H}$. Jalma, R. E. Putera, and K. Kusdarini, 2019).

Penggunaan dan instalasi OpenSID sangatlah mudah. Tutorial untuk instalasi hingga penggunaan telah lengkap dan dapat diunduh pada http://bit/ly/panduanopensid-pdf. OpenSID menyediakan dashboard yang dapat diatur dari menu, berita, hingga gambar pada slider.

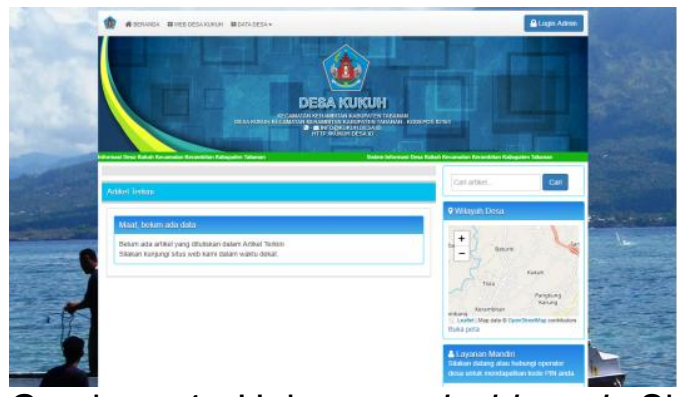

Gambar 4 Halaman dashboard Sistem Informasi Desa Kukuh

Kebutuhan logo dan data tentang profil desa disediakan oleh aparatur Desa
Kukuh. Adapun perubahan OpenSID untuk sistem informasi Desa Kukuh hanya dilakukan pada fasilitas pengaturan "Identitas Desa".

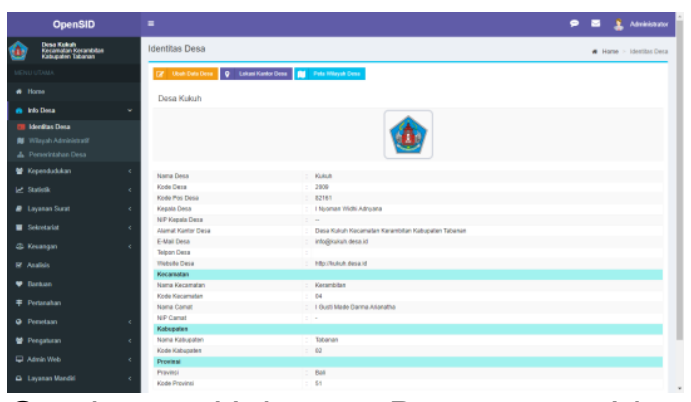

Gambar 5 Halaman Pengaturan Identitas Desa

Pengaturan ini dapat diubah sesuai dengan kebutuhan pada masa mendatang. Dengan pengaturan yang telah dilakukan, sistem informasi Desa Kukuh telah siap digunakan.

5) Pengenalan Sistem Informasi Desa

Pelaksanaan kegiatan pengabdian kepada masyarakat di Desa Kukuh Kecamatan Kerambitan Kabupaten Tabanan adalah mengimplementasikan aplikasi sistem informasi desa dan kependudukan berbasis web. Sistem Informasi Desa dan Kependudukan Berbasis Web di Desa Kukuh bertujuan untuk membantu para Aparatur Desa Kukuh membagikan informasi yang bersifat publik, dan sekaligus untuk membantu masyarakat desa mendapatkan informasi secara real time.

6) Kendala Implementasi Sistem Informasi

Penerapan teknologi informasi untuk administrasi desa dan kependudukan mengubah sebagian besar proses bisnis yang saat ini dilakukan pada kantor Desa Kukuh. Perubahan ini mengakibatkan adanya penurunan kinerja sementara karena penyesuaian dengan penerapan proses bisnis baru yang menggunakan sistem informasi desa dan kependudukan. Kinerja aparatur desa akan meningkat bahkan melebihi proses bisnis lama pada saat teknologi informasi telah fasih digunakan. Penerapan teknologi membutuhkan pelatihan dan waktu agar aparatur desa dapat terbiasa dalam 
menggunakan Sistem informasi desa dan Kependudukan.

\section{KESIMPULAN}

Pelaksanaan pengabdian kepada masyarakat tentang implementasi Sistem Informasi Desa dan Kependudukan Berbasis Web di Desa Kukuh Kecamatan Kerambitan kabupaten Tabanan telah terlaksana secara maksimal dengan metode partisipatif yang dilakukan dengan tiga tahap, yaitu 1) Tahap pendaftaran domain desa.id ke Kementerian Komunikasi dan Informatika; 2) Tahap penyiapan server dan hosting dengan memanfaatkan jasa para vendor web hosting, serta 3) implementasi Sistem Informasi Desa dan Kependudukan.

Penerapan sistem informasi dapat mengakibatkan penurunan kinerja sementara karena penyesuaian dengan penerapan proses bisnis baru yang menggunakan sistem informasi desa dan kependudukan. Kinerja aparatur desa akan meningkat bahkan melebihi proses bisnis lama pada saat teknologi informasi telah fasih digunakan. Penerapan teknologi membutuhkan pelatihan dan waktu agar aparatur desa dapat terbiasa dalam menggunakan Sistem informasi desa dan Kependudukan.

\section{DAFTAR PUSTAKA}

Undang-Undang Nomor 14 Tahun 2008 tentang Keterbukaan Informasi Publik," 2008.

Wibawa, K. C. S. 2019. "Urgensi Keterbukaan Informasi dalam Pelayanan Publik sebagai Upaya Mewujudkan Tata Kelola
Pemerintahan yang Baik," Adm. Law Gov. J.,.

Setligt, A. O. 2017. "Kajian Hukum Pelaksanaan Keterbukaan Informasi Publik Berdasarkan Undang-Undang Nomor 14 Tahun 2008 Tentang Keterbukaan Informasi Publik," LEX Priv.

Riyanto, I. Santiko, and A. M. Wahid, 2018. "Sistem Informasi Kependudukan dan Pelayanan Administrasi Desa," in CITISEE 2018,.

Kariadi, I. N. 2017. "Kecamatan Kerambitan Dalam Angka 2017," Tabanan.

Kemkominfo, 2016. "Pendaftaran Nama Domain .desa.id,". [Online].

Available:

https://domain.go.id/PendaftaranDom ainDesa.pdf. [Accessed: 18-Jan2020].

Mirheidari, S. Arshad, and S. Khoshkdahan, 2012. "Performance evaluation of shared hosting security methods," in Proc. of the 11th IEEE Int. Conference on Trust, Security and Privacy in Computing and Communications, TrustCom-2012 11th IEEE Int. Conference on Ubiquitous Computing and Communications, IUCC-2012.

Behrouz A. Forouzan Fegan, 2012. "Data communications and networking 5th Edition," in McGraw-Hill Forouzan Networking Series,

H. Jalma, R. E. Putera, and K. Kusdarini, 2019. "E-Government dengan Pemanfaatan Web OpenSID dalam Pelayanan Publik di Nagari Tanjung Haro Sikabu-kabu Padang Panjang," Publik (Jurnal IImu Adm., 2019. 